\title{
VULNERABILIDADE AMBIENTAL DA PLANÍCIE COSTEIRA DE CARAVELAS (BA) COMO SUBSÍDIO AO ORDENAMENTO AMBIENTAL
}

\author{
Environmental Vulnerability of the Caravelas (BA) Coastal Plain as Subsidy to Environmental \\ Planning
}

\author{
Sírius Oliveira Souza \\ biogeografia1@gmail.com \\ Universidade Estadual de Campinas - UNICAMP, Campinas, São Paulo, Brasil \\ Cláudia Câmara do Vale \\ camaravale@gmail.com \\ Universidade Federal do Espírito Santo - UFES, Vitória, Espírito Santo, Brasil
}

Artigo recebido em 22/07/2014 e aceito para publicação em 16/02/2016

RESUMO: A pressão de uso sobre as zonas costeiras e os seus efeitos sobre o equilíbrio dos ecossistemas têm sido um assunto, frequentemente, abordado na literatura científica. Tal situação leva os planejadores a procurarem sintetizar a informação científica para desenvolver modelos de estudos costeiros integrados. A partir destes estudos, objetivar-se-á neste trabalho analisar a vulnerabilidade ambiental da Planície Costeira de Caravelas, no Estado da Bahia (Brasil), por meio de técnicas de geoprocessamento, com o intuito de subsidiar o ordenamento ambiental. Nesta pesquisa foram elaborados índices de vulnerabilidade ambiental a partir da integração das características geológicas, pedológicas, clinográficas e de uso e ocupação da terra. As classes que apresentam vulnerabilidade muito alta e alta incluem os manguezais, os ambientes flúviolagunares e a linha de costa. Na classe que apresenta vulnerabilidade ambiental média estão incluídas áreas da planície costeira e as encostas dos tabuleiros. As classes de baixa e muito baixa vulnerabilidade abrangem os topos dos tabuleiros costeiros situados no trecho noroeste da área em estudo. Os resultados encontrados permitiram a compreensão dos diferentes graus de vulnerabilidade de cada unidade frente a determinadas pressões antrópicas, podendo ser utilizado como instrumento de ordenamento ambiental local e regional.

Palavras-chave: Geomorfologia costeira; Planejamento; Vulnerabilidade

ABSTRACT: The use pressure on coastal zones and their effects on the equilibrium of ecosystems have been a subject often discussed in the scientific literature. This situation takes the planners to look for summarize the scientific information to develop models of integrated coastal studies. From these studies, this paper aims to analyze the environmental vulnerability of the Caravelas Coastal Plain in the state of Bahia (Brazil) by means of geoprocessing techniques in a Geographic Information System, with the purpose of subsidize the environmental planning. Lastly, this research has generated environmental vulnerability levels as

DOI: http://dx.doi.org/10.1590/1982-451320160110 
from the integration of geological, soil conditions, slope and use and occupation of land characteristics. The classes that have high and very high vulnerability include mangroves, the floodplains and shoreline. In the class that has an average environmental vulnerability is included areas of the coastal plain and the slopes of the trays. The classes of low and very low vulnerability include the trays located at the northwest portion of the study area. The results obtained allowed understand the different degrees of vulnerability of each unit front of some human pressures, can be used as a tool for local and regional environmental planning.

Keywords: coastal geomorphology; planning; vulnerability.

\section{INTRODUÇÃO}

A funcionalidade dos ambientes naturais é alterada pelas ações humanas em um ritmo mais intenso que aquele normalmente produzido pela própria natureza. Quando não planejadas, tais alterações proporcionam uma série de desequilíbrios funcionais que, muitas vezes acarretam consequências drásticas à vida humana e à própria natureza. Afinal, segundo Ross (2006, p.56): "[...] As inserções humanas, por mais estruturadas que possam ser, não criam natureza, não modificam as leis da natureza, apenas interferem nos fluxos de energia e matéria alterando suas intensidades, forçando a natureza a encontrar novos pontos de equilíbrio funcional. ".

Exemplos desses desequilíbrios ambientais podem ser visualizados na maioria dos municípios situados ao longo do litoral brasileiro. Estes, nas últimas décadas sofreram com a implantação imprópria de novas formas de uso e ocupação da terra. Entendendo o uso e a ocupação da terra enquanto distintas formas de utilização e apropriação do espaço por parte das sociedades humanas (IBGE, 2006), o desmatamento, o lançamento de efluentes nos cursos de água, o aterramento e construção em zonas costeiras denunciam a falta de preocupação com o ordenamento e gestão territorial. Tais formas, muitas vezes, não consideraram a vulnerabilidade ambiental destas áreas, causando danos irreversíveis aos ecossistemas presentes.

Ao entender vulnerabilidade ambiental como a maior ou menor susceptibilidade de um ambiente a um impacto potencial provocado pelo uso antrópico (TAGLIANI, 2002), evidencia-se que a avaliação da capacidade de suporte da paisagem se constitui, na atualidade, uma necessidade para se evitar o comprometimento dos recursos naturais e a potencialização de processos morfogenéticos negativos.

Com 8.698 km de extensão e área aproximada de 514 mil km², o litoral brasileiro constitui-se em um contínuo desafio à gestão em face da diversidade de problemáticas aí existentes. São aproximadamente 300 municípios defrontantes com o mar, os quais têm, na faixa de praia, um espaço privilegiado para o desenvolvimento de atividades turísticas, de lazer, de pesca, dentre outras (NICOLODI; PETERMAN, 2010).

É nesse cenário dinâmico e de alta mobilidade, tanto física quanto socioeconômica, que residem aproximadamente $26 \%$ da população do país, sendo que 16 das 28 regiões metropolitanas encontram-se no litoral. Essas áreas de adensamento populacional convivem com amplas extensões de povoamento disperso e rarefeito. São os habitats das comunidades de pescadores artesanais, dos remanescentes de quilombos, de tribos indígenas e de outros agrupamentos imersos em gêneros de vida tradicionais (NICOLODI; PETERMAN, 2010).

O litoral, como recorte regional para estudo e como base para o tratamento de políticas públicas é uma realidade, tendo em vista a densa ocupação desta área, gerada, dentre outros fatores, por distintos méritos, tais como disponibilidade de recursos naturais, facilidade de acesso, a proximidade com a costa propriamente dita e a beleza cênica. Esses interesses se relacionam de forma intensa na produção do espaço, ora se integrando, ora competindo e oportunizando o surgimento de conflitos. Assim, o Brasil insere-se, historicamente, no processo de concentração produtiva e, consequentemente, populacional do litoral (MORAES, 2007).

Ainda segundo Moraes (2007) na zona 
costeira do estado da Bahia, a densidade demográfica média é de $96 \mathrm{hab} / \mathrm{km}^{2}$. Tal dado se encontra acima da densidade nacional que é de $22 \mathrm{hab} / \mathrm{km}^{2}$, segundo o mesmo autor. No entanto esse valor é baixo em relação aos estados de Pernambuco e do Rio de Janeiro com $913 \mathrm{hab} / \mathrm{km}^{2} 806 \mathrm{hab} / \mathrm{km}^{2}$, respectivamente. Dessa forma, em função da moderada densidade populacional da costa da Bahia, a mesma pode ainda ser planejada/pensada de forma a minimizar a vulnerabilidade encontrada em outros trechos da costa brasileira.

Ao longo do litoral baiano, optou-se por estudar a Região Planície Costeira de Caravelas, localizada no extremo sul do estado, com cerca de 580 $\mathrm{km}^{2}$ de área, compreendendo parte dos municípios de Alcobaça, Nova Viçosa e Caravelas. A escolha justifica-se pela sua extensão quando comparada com as demais planícies costeiras do Brasil, bem como pela sua representatividade ecológica, considerada um santuário ecológico, atestado pela existência da Reserva Extrativista de Cassurubá.

Diante disso, tornou-se imperativo realizar um trabalho que ao mesmo tempo em que produza informações e conhecimento sobre uma área localizada nesta porção do litoral, seja um instrumento útil para subsidiar planejamentos, zoneamentos e a gestão de uso e ocupação da terra em regiões costeiras. Desta forma, este trabalho tem por objetivo analisar a vulnerabilidade ambiental da Região Planície Costeira de Caravelas como subsídio ao ordenamento ambiental.

\section{MATERIAIS E MÉTODOS}

\section{Caracterização da área em estudo}

A Região Planície Costeira de Caravelas se localiza no extremo sul do estado da Bahia, na faixa costeira denominada Costa das Baleias, abrangendo parte dos municípios de Alcobaça, Caravelas e Nova Viçosa (Figura 1). Situando-se entre os paralelos $17^{\circ} 37^{\prime} 52^{\prime \prime}$ S e $17^{\circ} 51^{\prime} 44^{\prime \prime}$ S e os meridianos $39^{\circ} 22^{\prime} 7^{\prime \prime}$ e $39^{\circ} 12^{\prime} 7.11^{\prime \prime} \mathrm{W}$ de Greenwich, esta planície se limita ao norte pela bacia do rio Itanhém, ao sul e a oeste pela bacia do rio Peruípe e a leste com o oceano Atlântico.

O clima da região é classificado como do tipo tropical, superúmido à úmido, sem estação seca (IBGE, 2007). A análise do regime pluviométrico da área em estudo evidencia uma perda gradativa da precipitação do litoral em direção ao interior do continente, com valores na costa em torno de 1.350 $\mathrm{mm}$ e em áreas continentais próximas de $1.050 \mathrm{~mm}$ ao ano (SOBRINHO, 2008). O que contribui para o desenvolvimento dos seguintes tipos de cobertura vegetal: Floresta Ombrófila Densa e Formações Pioneiras (DOMINGUEZ, 2008).

Tomando como base os remanescentes e gradientes ecológicos, Dominguez (2008) descreve que na região estudada ocorre a Floresta Ombrófila Densa (Mata Atlântica) ocupando os Tabuleiros Costeiros e as porções mais úmidas das serras próximas ao litoral. Tal formação conglomera um diversificado mosaico de ecossistemas florestais com estruturas e composições florísticas bastante individualizadas, tendo como elemento comum a exposição aos ventos úmidos oceânicos. Ainda segundo o autor, restam apenas alguns remanescentes desta cobertura vegetal ajustados nas vertentes dos vales da Formação Barreiras, determinada principalmente por sedimentos areno-argilosos de idade neógena. Tal conjuntura se faz principalmente em razão da introdução de áreas de pastagens, silvicultura, sobretudo eucalipto, e lavouras de ciclos curtos. 
Figura 1 - Mapa de Localização da Planície Costeira de Caravelas.

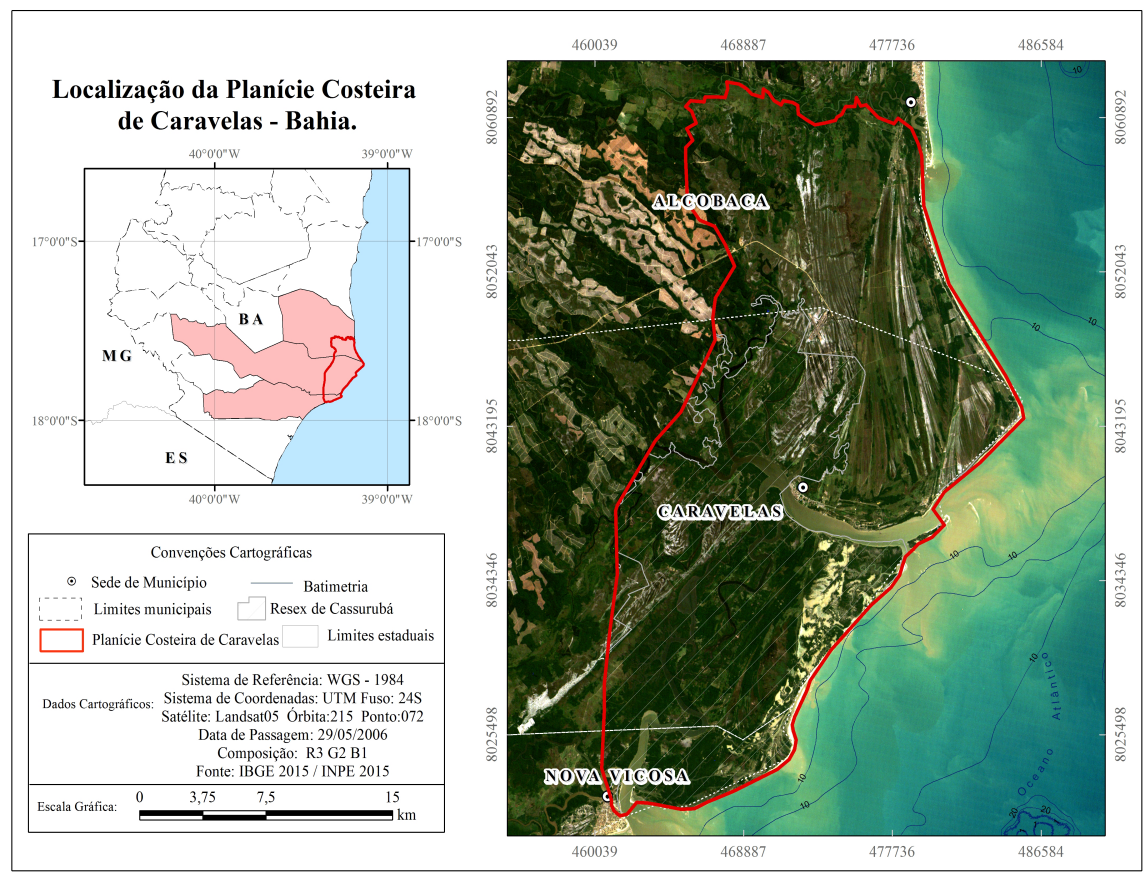

Org. os autores.

No que se refere às Formações Pioneiras, Dominguez (2008) elucida que as mesmas abrangem áreas de influência marinha, fluvial e flúviomarinha. As áreas de influência marinha compreendem aos espaços cujo substrato arenoso é coberto por vegetação do tipo mata seca de restinga. Enquanto as áreas de influência fluvial, sujeitas às inundações cíclicas ao longo dos rios são recobertas por formações herbáceo-graminóides. Já as áreas de influência flúviomarinha são caracterizadas pelas oscilações das marés e substrato argiloso, no qual se desenvolvem a vegetação que compõe os manguezais. Embora tenham sido pontualmente alteradas, segundo o autor, tais formações encontram-se ainda bem conservadas.

Em âmbito geológico-geomorfológico, a Região Planície Costeira de Caravelas está assentada secundariamente sobre os sedimentos arenoargilosos de idade terciária da Formação Barreiras, que se distinguem pela existência de vales profundos e bordas escarpadas, e uma superfície geral inclinada em direção ao litoral, constituindo os tabuleiros costeiros. E principalmente sobre a planície quaternária, constituída por depósitos de areias litorâneas regressivas pleistocênicas e holocênicas, denotando a formação de cordões litorâneos cordões, que são acumulações alongadas, em geral de composição arenosa dispostas paralelamente a paleolinhas praiais, por vezes interrompida por cursos d'água e separada entre si por zonas baixas. Tais depósitos encerraram sua acumulação controlada pelas variações do nível relativo do mar que afetaram a costa brasileira durante o Quaternário (ANDRADE; DOMINGUEZ, 2002).

A formação dos solos nesta área em estudo está diretamente associada às distintas unidades geológico-geomorfológicas presentes. Assim, nos sedimentos que compõem os tabuleiros costeiros, instalam-se processos pedogenéticos que deram origem aos Argissolos Amarelos Distróficos, Latossolos Vermelhos, Vertissolos, dentre outros. Nas planícies fluviais e fluviomarinhas, instalamse processos que originam os Espodossolos Hidromórficos, Gleissolos Háplicos e Organossolos Háplicos. Por fim, nos sedimentos que compõem 
os cordões litorâneos das planícies quaternárias, implantam-se os Neossolos Quartzarênicos (ANDRADE, 1994).

Segundo Souza (2013) 93\% da Região

Planície Costeira de Caravelas apresentam declividade de $0 \%$ a $2 \%$, sendo consideradas por Young (1981) apud Oliveira (2003) como espaços com maior propensão a inundações. Tal porcentagem corresponde a uma área de $539 \mathrm{~km}^{2}$. Observa-se, ainda, que apenas $7 \%$ da área em estudo apresentam declividade superior a $2 \%$ sendo classificados como superfícies planas e/ou levemente onduladas. Neste domínio, onde ocorrem as planícies costeiras, a declividade varia de 0 a $15 \%$, o que pela Lei ${ }^{\circ}$ 6.766/1979, em seu artigo $3^{\circ}$, dispõe-se como área suscetível à urbanização sem restrições. Logo, evidencia-se o seu potencial urbano, e justifica-se a necessidade de um planejamento pautado na análise da vulnerabilidade ambiental presente.

Quanto à caracterização demográfica, de acordo com o Censo Demográfico do Instituto Brasileiro de Geografia e Estatística (IBGE, 2010), a RegiãoPlanícieCosteiradeCaravelas,aocompreender a cidade de Caravelas, sede do município, e algumas vilas e povoados, contava com um contingente populacional de 21.414 habitantes. Estes habitantes se ocupam economicamente principalmente com atividades tradicionais (pecuária, pesca e agricultura de subsistência), embora a silvicultura do eucalipto e o turismo constituam os vetores mais dinâmicos da economia regional e os principais responsáveis pelas recentes transformações ambientais e socioprodutivas.

Nesta perspectiva a urbanização dos municípios inclusos na área em estudo tem se dado por meio da expansão de bairros periféricos, incorporados à mancha urbana. Em virtude de ser um processo ainda em expansão, essas áreas periféricas se caracterizam pelo alto incremento demográfico, baixo nível de renda, sérios problemas de infraestrutura e escassas condições de saúde e educação, com tendências a ampliar substancialmente os danos até agora provocados e a comprometer o futuro social e ambiental do lugar e até mesmo a chamada vocação turística, que poderá estar ameaçada com índices de pobreza, miséria e degradação do ambiente
Atualmente, a ocorrência de ocupações silvipastoris em ambientes de preservação ambiental, tais como a Reserva Extrativista de Cassurubá (Figura 1) afronta a ideia de desenvolvimento urbano sustentável, e se constitui em exemplos de modelos e processos econômicos, socialmente e ambientalmente inadequados. A inexistência de definições e limites legais de uso e ocupação da terra, contribuem para a permanência desses processos de ocupação inadequada. $\mathrm{O}$ que demanda a necessidade por um estudo que vise a delimitação de vulnerabilidade ambiental da área, e que, ao mesmo tempo, possa ser útil ao planejamento de uma ocupação adequada.

\section{Procedimentos Metodológicos}

Para alcançar os objetivos propostos neste estudo, ele foi dividido em três principais etapas: a primeira é composta de revisão bibliográfica acerca da vulnerabilidade ambiental em planícies costeiras; a segunda, composta pela elaboração da cartografia básica e aquisição das imagens. A terceira etapa é caracterizada pela integração dos dados e aplicação do índice de vulnerabilidade ambiental em ambiente SIG, com uso do software ArcGIS ${ }^{\mathrm{TM}} 10.1$ e pela redação final da pesquisa. Apresenta-se a seguir, o detalhamento dos principais procedimentos relativos à segunda e à terceira etapa.

Considerando a identificação da vulnerabilidade ambiental por meio da proposta metodológica de Nascimento e Dominguez (2009) que faz uso das variáveis dispostas na Tabela 1 procedeu-se o desenvolvimento de rotinas de geoprocessamento. Iniciando pela produção da cartografia básica através da aquisição de duas cartas topográficas digitais em escala 1:100.000 referentes a área em estudo: Caravelas SE.24-V-D-VI 2394 e Mucuri SE.24-Y-B-II 243, ambas fornecidas pela Superintendência de Estudos Econômicos e Sociais da Bahia - SEI (2012) e processadas com a utilização do software ArcGis ${ }^{\mathrm{TM}}$ 10.1. 
Vulnerabilidade Ambiental Da Planície Costeira De Caravelas (Ba) Como Subsídio Ao Ordenamento Ambiental

Sirius Oliveira Souza, Cláudia Câmara do Vale

Tabela 1 - Variáveis utilizadas na determinação da vulnerabilidade ambiental.

\begin{tabular}{|l|l|l|}
\hline Variáveis & Critérios & Fonte e Escala do Material \\
\hline Geologia & Tempo geológico & Dominguez (2008) - 1:100.000 \\
\hline Solos & Maturidade pedogenética & Adaptado de SEI (2012) - em escala 1:100.000 \\
\hline Declividade & Variação de declividade & Elaborado com imagens SRTM-30 em escala 1: 100.000. \\
\hline Uso e ocupação da Terra & Tipo de uso & Souza (2015) em escala 1:100.000 \\
\hline
\end{tabular}

Fonte: Adaptado de Nascimento e Dominguez (2009)

Posteriormente, seguiu-se a adaptação e/ ou vetorização de algumas informações necessárias ao desenvolvimento da pesquisa, tais como o mapa geológico produzido por Dominguez (2008); o mapa pedológico elaborado pela Superintendência de Estudos Econômicos e Sociais da Bahia (SEI, 2012) e o mapa de uso e ocupação da terra elaborado por meio de classificação supervisionada híbrida de imagens LANDSAT-7 TM datadas do ano de 2011, detalhadamente exposto e descrito em Souza (2015).

Para a elaboração do mapa de declividade realizou-se a confecção de um Modelo Digital de Elevação (MDE) extraído do sensor ASTER (Advanced Spaceborne Thermal Emission and Reflection Radiometer), sendo denominado ASTER GDEM (Global Digital Elevation Model) com resolução espacial de 30 metros, disponibilizado de forma gratuita na homepage do serviço geológico do Japão: < http://gdem.ersdac.jspacesystems.or.jp//>.

Cabe lembrar que o sensor ASTER é um dos cinco dispositivos de sensoriamento remoto a bordo do satélite Terra (EOS-AM1), lançado pela NASA em 1999, é o instrumento do satélite Terra que oferece 14 canais que variam de 0,5 a $12 \mu \mathrm{m}$, contudo o intervalo de 0,76 a $0,86 \mu \mathrm{m}$ é captado duplamente (no Nadir e Off-Nadir) para geração de modelos digitais de elevação.

De posse de uma imagem ASTER GDEM datada de abril de 2013, seguiu-se a confecção da estrutura de grade triangular, também conhecida como Triangular Irregular Network (TIN), que possibilita a representação do relevo por um conjunto de faces triangulares. Para que este modelo seja gerado é necessário que se tenha em mãos as curvas de nível. Neste contexto, de posse da imagem aplicouse a ferramenta Fill para a correção de possíveis depressões espúrias, seguido pelo comando Spacial Anayst Tools e Countour para a geração das curvas, tendo as cotas de equidistância estabelecidas de $1 \mathrm{~m}$ em $1 \mathrm{~m}$.

Em seguida a ferramenta utilizada para a geração do TIN é o comando 3DAnalyste Creat/Modify TIN. Já com o TIN gerado foi utilizado a ferramenta 3D Analyst, e os comandos Surface Analysis e Slope para a identificação da declividade. Após esse procedimento, o modelo gerado foi reclassificado através da ferramenta Reclassify seguido da determinação manual das classes com base nos trabalhos de Souza (2013) e Oliveira (2003).

Como ilustrado na Tabela 2, delimitou-se seis classes de declividade distintas, na qual as duas primeiras classes (inferiores ou iguais a $2 \%$ ) representa as áreas sujeitas a inundações; enquanto a segunda classe $(2,01-5 \%)$ enquadra-se dentro do limite urbano industrial, utilizado em trabalhos de planejamento urbanos em regiões litorâneas efetuados segundo norma do IPT e Empresa Metropolitana de Planejamento da Grande São Paulo (OLIVEIRA, 2003).

Utilizando das variáveis descritas anteriormente na Tabela $1 \mathrm{em}$ formato raster procedeu-se o desenvolvimento da operação algébrica, atribuindo valores de 1 a 5 (sendo um pouco vulnerável e cinco altamente vulnerável) a cada critério e, posteriormente, somando-os, utilizando a ferramenta Reclassify e Intersect. $\mathrm{Na}$ sequência, para a determinação das classes de vulnerabilidade ambiental os valores atribuídos a cada classe foram interpolados, utilizando a ferramenta raster calculator. Os valores atribuídos são descritos na Tabela 02, 03, 04, e 05 e se baseiam nas pesquisas realizadas por Nascimento e Dominguez (2009), Tangliani (2002) e Crepani et al., (1996). 
Tabela 2 e 3 - Valores de vulnerabilidade ambiental para as unidades de declividade e unidades de Uso e Ocupação da Terra.

\begin{tabular}{|l|l|}
\hline Declividade $\%$ & $\begin{array}{l}\text { Valor de } \\
\text { Vulnerabilidade }\end{array}$ \\
\hline $0 \dashv 1$ & 5 \\
\hline $1 \dashv 2$ & 5 \\
\hline $2 \dashv 5$ & 2 \\
\hline $5 \dashv 10$ & 1 \\
\hline $10 \dashv 15$ & 3 \\
\hline $15 \dashv 23$ & 3 \\
\hline
\end{tabular}

\begin{tabular}{|l|l|l|}
\hline $\begin{array}{l}\text { Símbolo } \\
\text { das classes }\end{array}$ & Categorias & $\begin{array}{l}\text { Valor de } \\
\text { Vulnerabilidade }\end{array}$ \\
\hline TU/C & Área Urbana & $\mathbf{4 / 5}$ \\
\hline TA & Área Agrícola & $\mathbf{1 , 5 / 5}$ \\
\hline P & Pastagem & $\mathbf{4}$ \\
\hline TF & Área Florestal & $\mathbf{1 / 3}$ \\
\hline TU & Manguezais/brejos & $\mathbf{4 / 5}$ \\
\hline TA & Solo Exposto & $\mathbf{5}$ \\
\hline TCA & Corpos d'água & $\mathbf{5}$ \\
\hline
\end{tabular}

Fonte: Adaptado de Nascimento e Dominguez (2009) e Tagliani, (2002).

Tabela 04- Valores de vulnerabilidade ambiental atribuídos às diferentes classes de solos.

\begin{tabular}{|l|l|l|}
\hline $\begin{array}{l}\text { Letra símbolo } \\
\text { das classes }\end{array}$ & Classes de Solos & $\begin{array}{l}\text { Valor de } \\
\text { Vulnerabilidade }\end{array}$ \\
\hline GT/SM & Glei Tiomórfico/Solos Indiscriminados de Mangue & 5 \\
\hline OX & Organossolo Háplico & 5 \\
\hline GXbd & Gleissolo Háplico & 5 \\
\hline RUbe & Neossolo Flúvico Tb eutrófico & 4 \\
\hline RQg & Neossolo Quartzarênico Hidromórfico & 4 \\
\hline EKg & Espodossolo Hidromórfico & 3 \\
\hline PVAd & Argissolo Vermelho-Amarelo distrófico & 2 \\
\hline LAd & Latossolo Amarelo distrófico & 1 \\
\hline LVAd & Latossolo Vermelho-Amarelo distrófico & 1 \\
\hline
\end{tabular}

Fonte: Adaptado de Crepani et al. (1996). 
Tabela 05 - Valores de Vulnerabilidade Ambiental para as unidades litológicas.

\begin{tabular}{|c|c|c|}
\hline Símbolo & Litologia & $\begin{array}{l}\text { V a l o r d d e } \\
\text { Vulnerabilidade }\end{array}$ \\
\hline QHm & $\begin{array}{l}\text { Quaternário-Holoceno. } \\
\text { Depósitos argilo-orgânicos de mangue; ricos em matéria orgânica; }\end{array}$ & 5 \\
\hline QHla & $\begin{array}{l}\text { Quaternário - Holoceno } \\
\text { Depósitos de areias litorâneas atuais; Areias finas a médias bem } \\
\text { selecionadas; barras de rios e pontais arenosos. }\end{array}$ & 5 \\
\hline QHtu & $\begin{array}{l}\text { Quaternário-Holoceno } \\
\text { Depósitos argilo-orgânicos; sedimentos argilosos ricos em matéria } \\
\text { orgânica as vezes capeados por camadas de turfa; brejos e pântanos }\end{array}$ & 4,9 \\
\hline QHl & $\begin{array}{l}\text { Quaternário - Holoceno } \\
\text { Depósitos de areias litorâneas regressivas; areias finas a médias bem } \\
\text { selecionadas com estratificação plano-paralela de face da praia; cordões } \\
\text { litorâneos. }\end{array}$ & 4,75 \\
\hline QHfl & $\begin{array}{l}\text { Quaternário- Holoceno } \\
\text { Depósitos areno-argilosos fluviais; areias argilosas depositadas em } \\
\text { diques marginais e canais abandonados associados aos cursos d'água } \\
\text { atuais. }\end{array}$ & 4,6 \\
\hline QP1 & $\begin{array}{l}\text { Quaternário - Pleistoceno } \\
\text { Depósitos de areias litorâneas regressivas; areias finas a médias bem } \\
\text { selecionadas, restinga. }\end{array}$ & 4 \\
\hline QPla & $\begin{array}{l}\text { Quaternário - Pleistoceno } \\
\text { Depósitos de leques aluviais; sedimentos areno-argilosos com seixos. }\end{array}$ & 3,5 \\
\hline Qar & $\begin{array}{l}\text { Quaternário Indiferenciado } \\
\text { Areias quartzosas finas a muito grossas com grânulos e seixos de } \\
\text { quartzo. }\end{array}$ & 3,25 \\
\hline $\mathrm{Tb}$ & $\begin{array}{l}\text { Terciário } \\
\text { Formação Barreiras; sedimentos areno-argilosos. }\end{array}$ & 3 \\
\hline
\end{tabular}

Fonte: Adaptado de Nascimento e Dominguez (2009) e Crepani et al. (1996).

Desta forma, o índice de Vulnerabilidade Ambiental da Região Planície Costeira de Caravelas é resultado da média aritmética encontrada distribuída em cinco classes, com intervalos demonstrados na Tabela 06.

Tabela 06 - Média aritmética para as classes de Vulnerabilidade Ambiental.

\begin{tabular}{|l|l|}
\hline CLASSIFICAÇÃO & INTERVALOS \\
\hline Muito Baixa & $4-8$ \\
\hline Baixa & $8-10$ \\
\hline Média & $10-12$ \\
\hline Alta & $12-15$ \\
\hline Muito Alta & $15-19$ \\
\hline
\end{tabular}

Fonte: Adaptado de Nascimento e Dominguez (2009) 


\section{RESULTADOS E DISCUSSÕES}

A partir dos critérios e procedimentos descritos anteriormente, apresenta-se na Tabela 07 e na Figura 02 os resultados obtidos na análise da vulnerabilidade ambiental da Região Planície Costeira de Caravelas. Tais resultados demonstram que a área em estudo se enquadra em todas as classes dentro da metodologia proposta por Nascimento e Dominguez (2009), são elas: Muito Baixa, Baixa, Média, Alta e Muito Alta Vulnerabilidade.

Tabela 07 - Nível de Vulnerabilidade Ambiental da Região Planície Costeira de Caravelas.

\begin{tabular}{|l|l|l|}
\hline \multirow{2}{*}{ Nível de Vulnerabilidade Ambiental } & \multicolumn{2}{l|}{ Área } \\
\cline { 2 - 3 } & $\mathbf{( k m}^{\mathbf{2}}$ & $\mathbf{( \% )}$ \\
\hline Muito Baixa & 11,85 & 2,04 \\
\hline Baixa & 39,55 & 6,81 \\
\hline Média & 134,55 & 23,17 \\
\hline Alta & 323,91 & 55,79 \\
\hline Muito Alta & 70,64 & 12,16 \\
\hline
\end{tabular}

Org.: os autores.

Inicia-se a discussão pelas áreas de muito alta vulnerabilidade ambiental. Esta classe engloba 70,64 km² da Região Planície Costeira de Caravelas, cerca de $12,16 \%$ e inclui vastas áreas de Manguezais e brejos que ocupam as Planícies de maré, áreas rebaixadas e espaços de Solo Exposto. Essa classe engloba, portanto, os ecossistemas mais sensíveis da região. Estes estão sujeitos às inundações, seja, pelas águas pluviais, seja pelo transbordamento dos rios, ou mesmo pelas marés, que funcionam como fatores restritivos ao uso agrícola.

As áreas de muito alta vulnerabilidade ambiental são cortadas por inúmeros canais, que servem de dutos para a entrada e saída das marés. Configuram ambientes totalmente instáveis por estarem sujeitos às inundações fluviais, pluviais e marinhas periódicas. Incluem-se trechos da linha de costa, apresentando em alguns pontos erosão costeira moderada, como no trecho norte da Ponta da Baleia, que se relaciona a mudanças na desembocadura do rio Itanhém em Alcobaça (BA). 
Figura 2 - Mapa de Vulnerabilidade Ambiental da Planície Costeira de Caravelas.
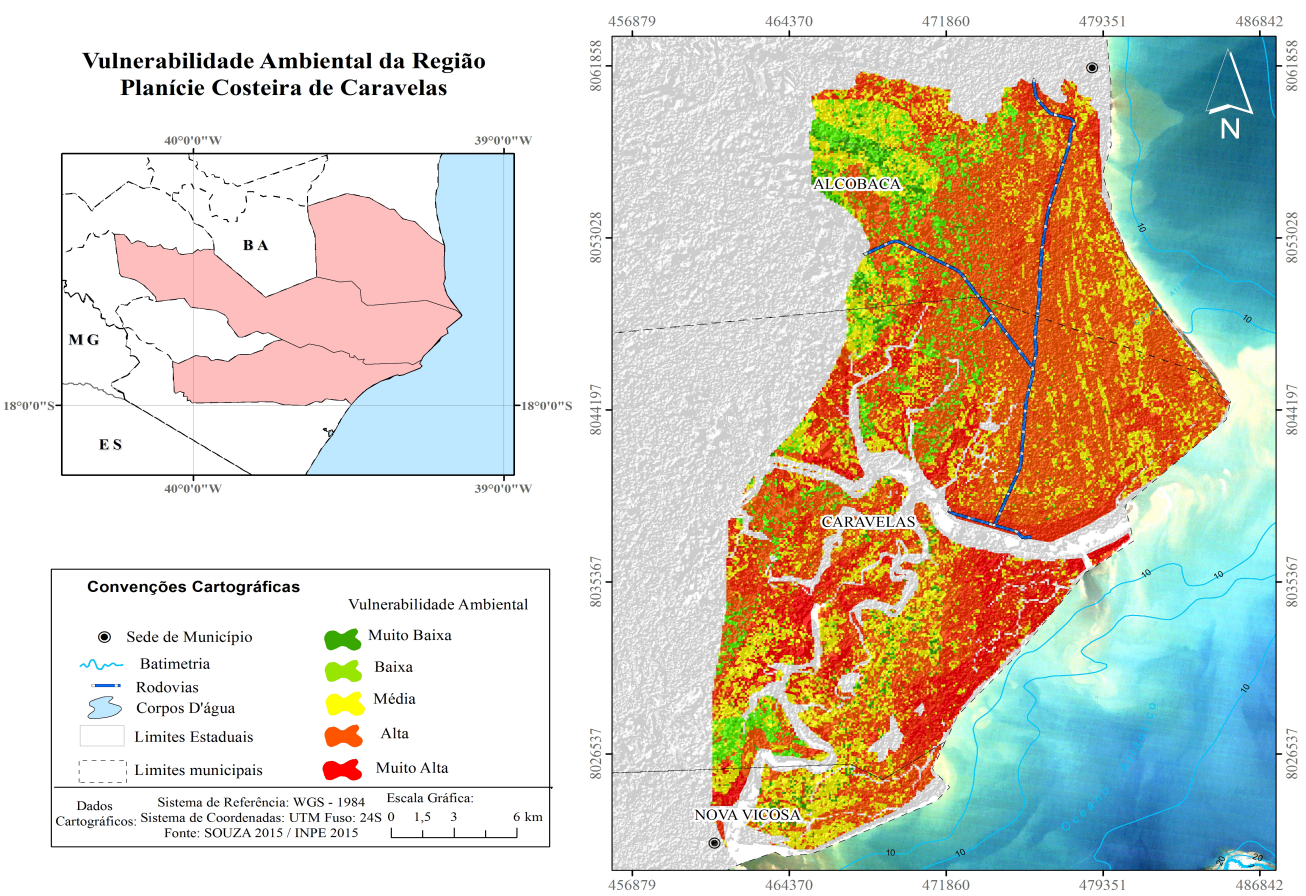

Org. os autores.

A figura 3 ilustra a região ao sul do canal de Caravelas, na Ilha de Cassurubá, classificada por este estudo como uma das áreas de muito alta vulnerabilidade ambiental.

Figura 3 - Detalhe de região de muito alta vulnerabilidade ambiental a ação antrópica na região da RESEX de Cassurubá.

Q Google Earth

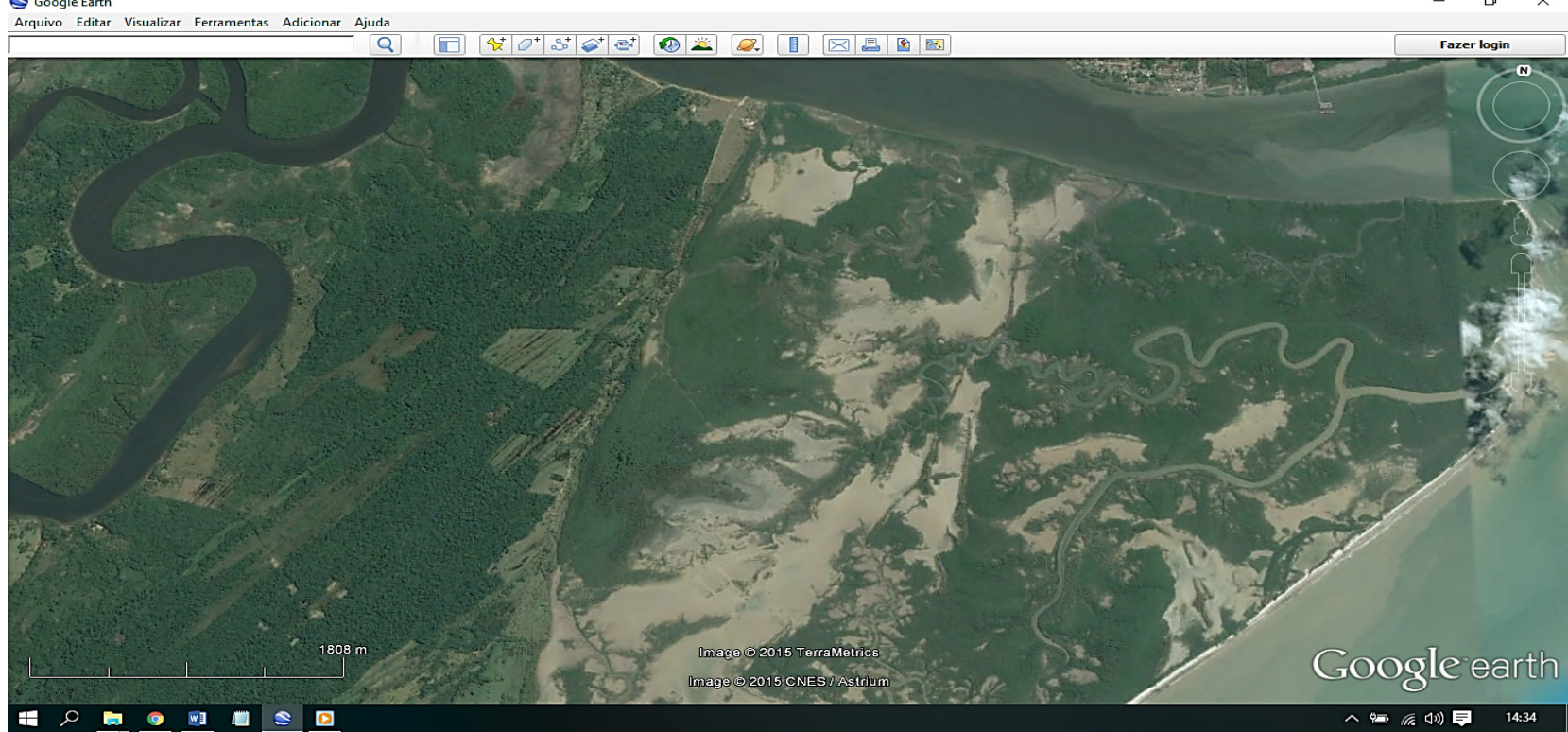

Fonte: Google Earth ${ }^{\mathrm{TM}}, 2015$.

Soc. \& Nat., Uberlândia, 28 (1): 147-160, jan/abr/2016 
Nesta região os depósitos arenosos apresentam pouca espessura e assentam-se diretamente sobre lamas plásticas de cor cinza, de origem marinha. Conforme Andrade e Dominguez (2002, p.14) estas lamas plásticas, sobre as quais os Terraços Arenosos estão assentados podem alterar as propriedades físicas do substrato e causar problemas geotécnicos (deformação e afundamento de obras de engenharia).

Nesta perspectiva, as áreas de muito alta vulnerabilidade ambiental, se apresentam topograficamente muito baixas, predominando os Organossolos e os Gleissolos, solos que comprovadamente manifestam um risco de contaminação elevado, além de serem solos plásticos e, portanto, incapazes de suportar a ocupação antrópica, tais como casas, estradas, empreendimentos, sem deformação.

Desta forma, qualquer ocupação nestas áreas implicaria a realização de aterros e, consequentemente, a eliminação deste ambiente. Portanto sugere-se enquanto medida de ordenamento ambiental a total conservação desta unidade, aliada a manutenção da Reserva Extrativista de Cassurubá. Uma vez que sua ocupação é particularmente problemática devido a reduzida profundidade do lençol freático e à plasticidade dos solos.

Na Região Planície Costeira de Caravelas predomina a categoria alta vulnerabilidade ambiental ocupando uma área total de 323,91 $\mathrm{km}^{2}$, cerca de $55,79 \%$ e abrangendo os Terraços Arenosos, formados por depósitos de areias litorâneas regressivas quaternárias. São áreas bastantes planas e que apresentam micro relevo em forma de cordões litorâneos, morfologia constituída de cristas alternadas com áreas deprimidas úmidas, com o lençol freático aflorante. Em quase toda sua extensão preponderamse os Neossolos Quartzarênicos e Espodossolos Hidromórficos, recobertos pela vegetação Mata Seca de Restinga ou pela silvicultura de Eucalipto, tendo diversos usos associados, tais como: Pastagens, Áreas Agrícolas e Áreas Florestais.

A principal restrição à ocupação desta unidade é a sua baixa capacidade de retenção de impurezas decorrente de sua elevada permeabilidade, ausência de argila, baixo teor de matéria orgânica no solo e pela pequena profundidade em que se encontra a superfície piezométrica (ANDRADE; DOMINGUEZ, 2002).

Portanto sugere-se enquanto medida de ordenamento ambiental a preservação das áreas pertencentes à RESEX de Cassurubá e das áreas ainda não ocupadas e/ou alteradas e o monitoramento/ acompanhamento das áreas ocupadas e/ou alteradas. Visto que a descaracterização deste ambiente, ocorrida por meio de terraplanagem para implantação de atividade agropastoril, turística, ou mesmo residencial, certamente acarretará a destruição das cristas praiais, bem como da Mata Seca de Restinga, e o aterramento das depressões periodicamente inundadas, assumindo, portanto, caráter irreversível nesta paisagem, o que poderá condicionar um elevado risco à poluição dos recursos hídricos superficiais e subterrâneos presentes.

Sugere-se também que sejam constituídas nesta unidade, quando ao redor dos cursos fluviais, faixas de proteção e preservação segundo os critérios explicitados na resolução do CONAMA n ${ }^{\circ} 004 / 85$ e no Código Florestal Brasileiro Lei ${ }^{0} 12.651$, de 25 de maio de 2012 (BRASIL, 2013).

A classe de média vulnerabilidade ambiental compreende cerca de $134,55 \mathrm{~km}^{2}$, o que corresponde a $23,17 \%$ da área total. Esta classe ocorre predominantemente na planície costeira e secundariamente nos tabuleiros costeiros. $\mathrm{Na}$ planície costeira inclui em quase toda sua extensão os espodossolos, constituídos por sedimentos arenoargilosos, recobertos por vegetação Floresta Ombrófila Aluvial associada à atividade de pastagem.

Nos tabuleiros, a classe de média vulnerabilidade compreende as declividades entre $2 \%$ e $15 \%$, incluindo as pastagens, as culturas de cocoda-baía, e alguns trechos de silvicultura de eucalipto. Por apresentarem a maior parte de sua extensão dentro da área da RESEX, sugere-se enquanto medida de ordenamento ambiental a manutenção e acompanhamento destes ambientes. Visto que tais ambientes atuam enquanto áreas ecótonas, ou seja, de transição entre os ambientes de alta e de baixa vulnerabilidade.

As classes de Baixa vulnerabilidade ambiental e Muito Baixa vulnerabilidade ambiental somadas apresentam apenas $51,4 \mathrm{~km}^{2}$, compreendendo cerca de $8,65 \%$ da área total. Juntas, estas classes ocorrem predominantemente nos Tabuleiros Costeiros, 
caracterizados por interflúvios planos entalhados por inúmeros vales em forma de "U", com paredes íngremes e fundo chato (DOMINGUEZ, 2008). Em quase toda sua extensão observam-se o Argissolo Amarelo Distrófico associado ao Espodossolo Hidromórfico, recobertos pelo cultivo de eucalipto, tendo como principal uso as Áreas Agrícolas.

Os depósitos desta unidade segundo Dominguez (2008) são constituídos por sedimentos areno-argilosos, pobremente selecionados, com permeabilidade moderada e níveis cimentados por óxido de ferro. Do ponto de vista geotécnico esta unidade não apresenta dificuldades à ocupação. Uma vez que os terrenos areno-argilosos apresentam boa capacidade de suporte sugere-se, enquanto medida de ordenamento que os interflúvios dos Tabuleiros sejam considerados como área de uso urbano e agrícola, controlado, dentro dos limites descritos na legislação ambiental brasileira. Buscando sempre medidas preventivas contra a degradação ambiental e que as atividades desenvolvidas nesta unidade sejam administradas devidamente levando-se em conta o tipo de carga poluidora e a capacidade de autodepuração do sistema, bem como a distância (vertical e horizontal), entre a fonte poluidora e os mananciais subterrâneos e superficiais.

Enquanto medida de ordenamento ambiental, sugere-se que sejam consideradas como áreas de preservação permanente os remanescentes da província Mata Atlântica, ameaçados pelos constantes desmatamentos, assim como os demais trechos previstos no Código Florestal brasileiro.

\section{CONSIDERAÇÕES FINAIS}

As análises das classes de vulnerabilidade ambiental da Região Planície Costeira de Caravelas mostraram que os sistemas naturais presentes apresentam dois diferentes graus de vulnerabilidade ambiental a ação antrópica. Na planície costeira predomina a alta e muito alta vulnerabilidade ambiental e nos tabuleiros a baixa e média vulnerabilidade ambiental, apesar das diferentes intensidades de uso da terra nestas áreas, prevalecendo de uma forma geral os condicionantes intrínsecos destes ecossistemas.

Deste modo, a identificação das cinco classes de vulnerabilidade apresentada neste estudo aponta alguns critérios de suporte para o planejamento do uso e da ocupação da terra, principalmente, naquelas áreas que apresentaram vulnerabilidade ambiental muito alta. Para estas áreas se devem estabelecer limitações de uso e ocupação amparadas pela legislação ambiental e pelos instrumentos de gestão vigentes, visando a conservação e restauração dos ecossistemas presentes.

Por outro lado, as áreas menos vulneráveis apresentam maiores potencialidades de uso, em face da maior sustentabilidade oferecida pelos solos mais estáveis, evoluídos e litologias antigas, como no caso dos tabuleiros do setor noroeste da área em estudo.

Percebe-se a necessidade do desenvolvimento de pesquisas nesta área, visando à valorização e preservação tanto do ambiente natural, quanto do patrimônio histórico-cultural, embasadas em instrumentos que contribuam na minimização dos efeitos negativos da ação antrópica.

Um estudo como este, se torna importante na medida em que pode ser utilizado como um norteador das políticas de gestão para esta parte da zona costeira e contribuir para que as novas ocupações e o desenvolvimento econômico e social sejam compatibilizados com a preservação ambiental. Fica claro a necessidade de estudos mais detalhados para se obter uma delimitação de uso mais "sustentável", que vise atender às necessidades do homem e à manutenção dos recursos costeiros.

\section{REFERÊNCIAS}

ANDRADE, A. C. S.; DOMINGUEZ J. M. L., Informações Geológico-Geomorfológicas como Subsídios a Análise Ambiental: o Exemplo da Região Planície Costeira de Caravelas - Bahia. Boletim Paranaense de Geociências, Curitiba. n. 51, 2002, pp.9-17.

BRASIL. Lei $\mathrm{n}^{\circ}$ 12.651, de 25 de maio de 2012. Dispõe sobre a proteção da vegetação nativa; altera as Leis $\mathrm{n}^{\text {os }} 6.938$, de 31 de agosto de 1981, 9.393, de 19 de dezembro de 1996 , e 11.428 , de 22 de dezembro de 2006; revoga as Leis nos 4.771 , de 15 de setembro de 1965, e 7.754, de 14 de abril de 1989, e a Medida Provisória no $2.166-67$, de 24 de agosto de

Soc. \& Nat., Uberlândia, 28 (1): 147-160, jan/abr/2016 
2001; e dá outras providências. Portal da Legislação: Leis Ordinárias. 2013. Disponível em: <http://www. planalto.gov.br/ccivil_03/_Ato2011-2014/2012/Lei/ L12651.html.> Acesso em: 15 Set. 2013.

BRASIL. Lei n. 6.766, de 19 de dezembro de 1979. Dispõe sobre o Parcelamento do Solo Urbano e dá outras Providências, Brasília, DF. Portal da Legislação: Leis Ordinárias. 2013.Disponível em: < http://www.planalto.gov.br/ccivil_03/leis/16766.htm>. Acesso em: 10 de Jan. 2014.

CREPANI, E.; MEDEIROS, J. S.; AZEVEDO, L. G.; HERNANDEZ FILHO, P.; FLORENZANO, T. G.; DUARTE, V.; Curso de sensoriamento remoto aplicado ao zoneamento ecológico-econômico: metodologia desenvolvida para subsidiar o Zoneamento EcológicoEconômico. INPE. São José dos Campos, 1996.

DOMINGUEZ, J. M. L. (org.). Costa das Baleias: Caracterização da Zona Costeira dos Municípios de Alcobaça, Caravelas, Nova Viçosa e Mucuri. Salvador: CBPM / UFBA - CPGG / LEC, 2008.

\section{INSTITUTO BRASILEIRO DE GEOGRAFIA E} ESTATÍSTICA - IBGE, Mapa de climas do Brasil, diretoria de geociências, 2007. < disponível em: http:// www.ibge.gov.br/home/geociencias/default_prod. shtm\#MAPAS. Acesso em: 18 de dez.2013.

INSTITUTO BRASILEIRO DE GEOGRAFIA E ESTATÍSTICA. Manual Técnico de Uso da Terra. Manuais Técnicos em Geociências, n. 7, 2. ed. IBGE. Rio de Janeiro. 2006.

INSTITUTO BRASILEIRO DE GEOGRAFIA E ESTATÍSTICA. Censo 2010. Disponível em: $<$ http:// censo2010.ibge.gov.br/>. Acesso em: 12 Dez. 2015.

MORAES, A. C. R. Contribuições para a gestão da zona costeira do Brasil: elementos para uma geografia do litoral brasileiro. São Paulo. Annablume, 2007.

NASCIMENTO, D. M. C.; DOMINGUEZ, J. M. L. Avaliação da vulnerabilidade ambiental como instrumento de gestão costeira nos municípios de
Belmonte e Canavieiras, Bahia. Revista Brasileira de Geociencias. Salvador, v.39, n.3, 2009, pp.395-408.

NICOLODI, J. L.; PETERMANN, R. M. Mudanças Climáticas e a Vulnerabilidade da Zona Costeira do Brasil: aspectos ambientais, sociais e tecnológicos. Revista da Gestão Costeira Integrada. Rio Grande, v. 10, n. 2, 2010, pp. 151-177.

OLIVEIRA, R. C. Zoneamento Ambiental como subsídio ao planejamento no uso da terra do município de Corumbatai-SP. Tese. (Doutorado em Geociências e Meio Ambiente). UNESP - Rio Claro, 2003. 141f.

ROSS, J. L. S. Ecogeografia do Brasil: Subsídios para planejamento ambiental. São Paulo: Editora Oficina de Textos, 2006.

SUPERINTENDÊNCIA DE ESTUDOS ECONÔMICOS E SOCIAIS DA BAHIA - SEI. Mapas digitalizados do Estado da Bahia: base de dados. Salvador: SEI, 2012. (CD-ROM).

SOUZA. S. O. Vulnerabilidade Ambiental da Planície Costeira de Caravelas (Bahia): Uma proposta geossistêmica. Dissertação, (Pós-Graduação em Geografia). UFES - Vitória, 2013. 137f.

SOUZA, S. O. Geotecnologias Aplicadas à Análise Espaço temporal do Uso e da Ocupação da Terra na Planície Costeira de Caravelas (BA). Boletim Goiano de Geografia. Goiânia. v. 35, n. 1, pp. 71-89, 2015. Disponível em: $<$ http://www.revistas.ufg.br/index. php/bgg/article/view/35485>. Acesso em: 15 Dez. 2015.

TAGLIANI, C. R. A.. Técnica para avaliação da vulnerabilidade de ambientes costeiros utilizando um Sistema Geográfico de Informações. Porto Alegre: Editora da UFRG, 2002. Disponível em: < http:// www.praia.log.furg.br/Publicacoes/2003/2003c.pdf >. Acesso em: 10 jan. 2014. 